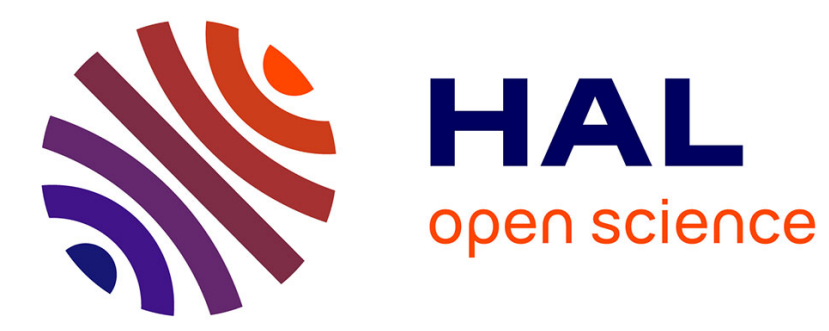

\title{
An economic study of control strategies for microgrids
}

Khaled Hajar, Ahmad Hably, Seddik Bacha, Ahmad Elrafhi

\section{To cite this version:}

Khaled Hajar, Ahmad Hably, Seddik Bacha, Ahmad Elrafhi. An economic study of control strategies for microgrids. REDEC 2018 - International Conference on Renewable Energies for Developing countries (REDEC 2018), Nov 2018, Beyrouth, Lebanon. 10.1109/REDEC.2018.8598121 . hal-01895346

\section{HAL Id: hal-01895346 \\ https://hal.science/hal-01895346}

Submitted on 15 Oct 2018

HAL is a multi-disciplinary open access archive for the deposit and dissemination of scientific research documents, whether they are published or not. The documents may come from teaching and research institutions in France or abroad, or from public or private research centers.
L'archive ouverte pluridisciplinaire HAL, est destinée au dépôt et à la diffusion de documents scientifiques de niveau recherche, publiés ou non, émanant des établissements d'enseignement et de recherche français ou étrangers, des laboratoires publics ou privés. 


\title{
An economic study of control strategies for microgrids
}

\author{
Khaled Hajar ${ }^{\diamond}$, Ahmad Hably *, Seddik Bacha *, Ahmad Elrafhi ${ }^{\diamond}$
}

\begin{abstract}
A centralized model predictive control algorithm (MPCA) and an optimal centralized control algorithm (OCCA) are applied on main grid connected with a group of interconnected microgrids (MGs). Maximizing the profit for all of the units constituting the MGs is the primary objective in both algorithms, further the advantages of the principle grid. A forcasting information about production power, energy price and loads is needed for the application of MPCA in our study. five interconnected MGs related to the principle grid are tested in this paper using the algorithm implemented in MATLAB. The performance of the proposed algorithms has been shown especially for the benefits of MG owners at the same time as respecting the constraints associated to every considered one of them. Then the results of OCCA and MPCA are compared technically and economically for each MG.
\end{abstract}

\section{NOMENCLATURE}

$P_{S, D}$ : Predicted power sold by the DSO $(\mathrm{kW})$.

$P_{S, M}$ : Predicted power sold by the MG $(\mathrm{kW})$.

$P_{B, D}$ : Predicted power bought by the DSO $(\mathrm{kW})$.

$P_{B, M}$ : Predicted power bought by the MG $(\mathrm{kW})$.

$P_{e q}$ : Power equilibrium.

$x_{e}$ : Stored energy $(\mathrm{kWh})$.

$\delta_{d i s, m}$ : Discharging efficiency of the ESS in the m-th MG.

$\delta_{\text {char, } m}$ : Charging efficiency of the ESS in the m-th MG.

$E_{\text {dis }}$ : Discharged energy $(\mathrm{kWh})$.

$E_{\text {cha }}$ : Charged energy $(\mathrm{kWh})$.

$m, n$ : MG index.

$M$ : MGs number.

$t$ : Control step.

$N_{c}$ : Control horizon.

$k$ : Prediction step.

$\hat{\psi}_{M}(k)$ : Scaling factor of buying power from the MGs.

$\psi_{M}(k)$ : Scaling factor of selling power to the MGs.

$\hat{\psi}_{D}(k)$ : Scaling factor of buying power from DSO.

$\psi_{D}(k)$ : Scaling factor of selling power to DSO.

$T_{S, D}$ : Expected tariff value of selling energy by the DSO $(€ / \mathrm{kWh})$.

$T_{S, M}$ : Expected tariff value of selling energy by the MG $(€ / \mathrm{kWh})$.

$T_{B, D}$ : Expected tariff value of buying energy by the DSO $(€ / \mathrm{kWh})$.

$T_{B, M}$ : Expected tariff value of buying energy by the MG $(€ / \mathrm{kWh})$.

\section{INTRODUCTION}

A MG is a small-scale power supply network. Loads, renewable energy sources (RES), distributed generation (DG), and energy storage systems (ESS) like hydraulic storage,

\footnotetext{
$\diamond$ Universite de Technologie et de Sciences Appliquees Libano-Francaise - Lebanon. khaled.hajaraulf.edu. lb
}

batteries, or even electrical vehicles, are the main MG's elements.

As intelligent distribution systems a $\mathrm{MG}$ is considered, with two dissimilar modes of operation: the isolated mode and the grid-connected mode [1].Due to the use of RES, the MG faces technical issue which is common for all MG obectives and characteristics. RES has random, intermittent, non programmable nature, which makes them hard to offer a continuous strength supply to remoted loads and to guarantee strength dispatch of RES in distribution grids.[2].

However, presenting enough technology ability, operational techniques and controls are expected to deliver at the least a part of the load, after being disconnected from the distribution system and stays operational as an remoted (self sustaining) entity[3]. Minimizing the operating cost such as

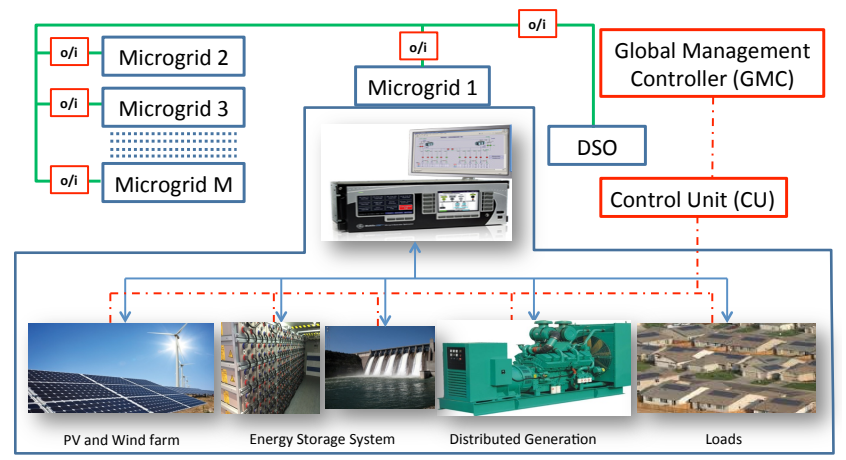

Fig. 1. Microgird units.

maintenance, purchase cost from the main grid and fuel is the general objective of an energy management of a MG [4]. The presence of MGs affords many benefits for the distribution system operators (DSO). Lower operation costs can be a benefit for the MGs and DSO owners. The clients can gain of a extra reliable and low cost energy supply. Further, the excess power produced via the MG can be offered to the DSO and vice-versa, which is taken into consideration as a gain for each parties. Therefore, it is indispensable to consider the networked MGs and DSO altogether[5].

MPC and optimization of a community of MGs are present in numerous works. In [6], under a layout based on a global model of the general system, a MPC has been proposed in which controllers are imagined to perform appart. A MPC on a set of interconnected MGs with the principle grid is implemented by Hajar et al.[7]. The authors of [8] make an research on decentralized linear quadratic Gaussian control (LQG) method. The authors have proposed an MPC for the most efficient power exchanges in a smart network of MGs 


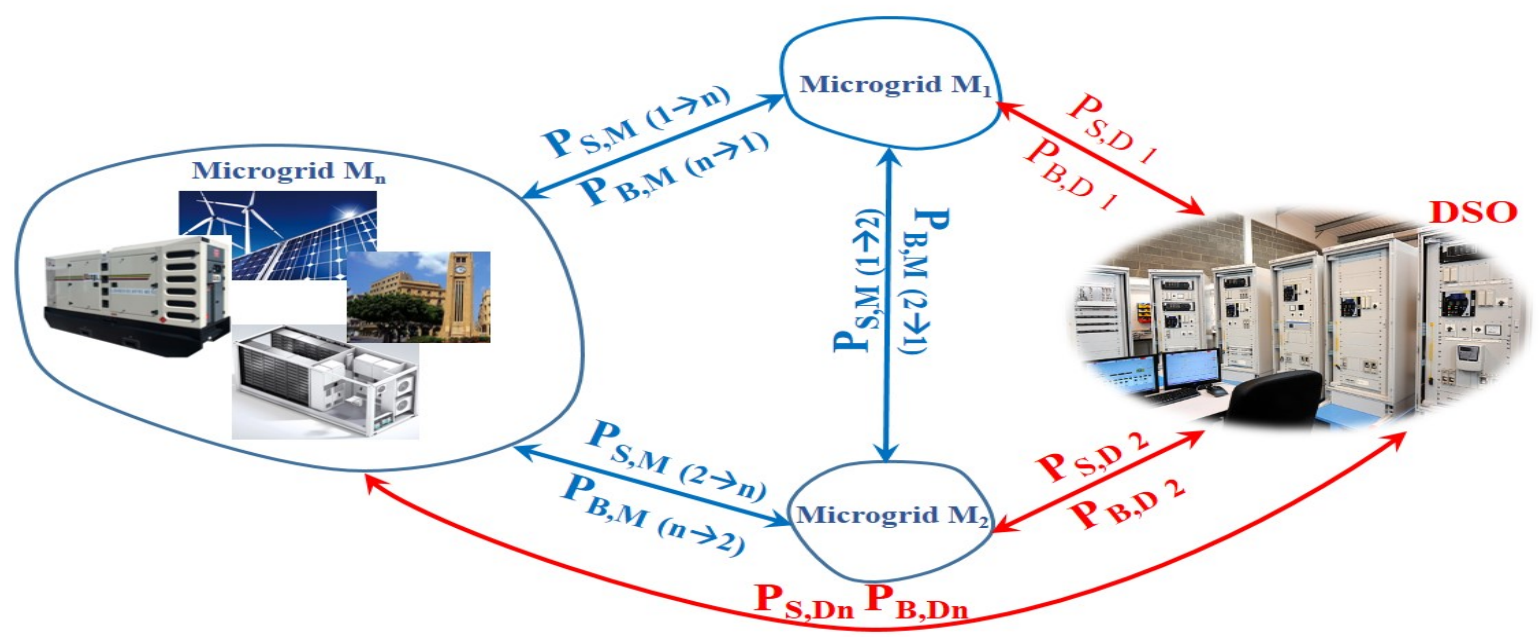

Fig. 2. Power flow in the grid (DSO+MG).

in [9]. Falahi et al. [10] propound, to regulate the reactive and active power in a MG, a MPC based energy management system.

In this introduced paper, we compare two control strategies of the power float among a network of interconnected MGs and with DSO, a centralized model predictive control algorithm (MPCA) and an optimal centralized control algoritm (OCCA). Even as maximizing the usage of renewable energy in every MG from one facet, and minimizing trade between MGs and DSO and the trade of power among neighboring MGs on the opposite side, this study assesses the economic earnings of all the actors of the Grid (DSO and all of the MGs).

This paper is organized as follows.In section II, MG units are provided. MG modeling in addition to MPCA and OCCA hassle are developed in section III. The results of the programs of the methodologies are afforded and commented in section IV-C. section $\mathrm{V}$ gives some conclusions and perspectives.

\section{MICROGRID UNITS}

In previous studies, numerous models for MG had been counseled. we've inspired of the modeling system counseled through [11] to generate our model of MG. Local loads, distributed generation, wind power, photovoltaic (PV), Energy storage systems (ESS), are incorporated in each MG. Also the inconstancy of solar irradiance and wind speed, affecting PV efficiency and the wind power respectively, are integrated. The different units of MG are provided in Fig.1 from our preceding work [2]. This figure also indicates the elements of producing or consuming power. A MG also can be linked or unlinked from DSO or/and can be linked to other MGs.

Depending on the energy production and the loads, ESS have three status: charging, discharging or stable. In our previous work [12], to maximise the power saved in ESS assuring the local intake a control unit (CU) is used. Global management Controller (GMC) is notified of the status of $\mathrm{CU}$ which optimize the manage of each MG. It gives a justification for if the MG has surplus of power or inversely. For each MG the goal can be accomplished by controlling starting or stopping DG, the discharge/charge of ESS and sending/receiving power to/from neighboring MGs. The GMC is devoted to aggregate, with a predicted control, the power in the grid, the relation with the DSO as well as between MGs. It takes additionally the decision anywhere the extra power is to be sell to DSO or to further MGs.

To resume, a MG includes:

- DSO offering/buying power to/from the MGs.

- Loads be regarded as consumers demand.

- RES supplying renewable energy.

- ESS enhancing the satisfactory and reliableness of supply.

- DG enhancing the reliability of supply.

- CU transferring the information to GMC.

\section{MICROGRIDS OPTIMIZATION AND STRATEGIES}

\section{A. Modeling}

The interaction between MGs is indicated in Figure 2 and among MGs and DSO alternatively. The saved power equation in every MG is right.

$$
\begin{aligned}
x_{e}(m, t+k)= & x_{e}(m, t+k-1)- \\
& \delta_{\text {dis }, m} E_{\text {dis }}(m, t+k)+ \\
& \delta_{\text {char }, m} E_{\text {char }}(m, t+k)
\end{aligned}
$$

\section{B. Optimization Formulation}

Our goal is to optimize the grid that the power generation, power balance, ESS, energy trade between MGs, energy trade among MGs and DSO are satisfied beneath certain constraints so as to be discussed in further section. 
The cost function $C$ to be minimized is presented via the subsequent equation:

$$
\begin{array}{r}
C=\sum_{k=1}^{N_{c}} \sum_{m=1}^{M} \sum_{n, n \neq m}^{M}\left[\psi_{M}(k) P_{S, M}(m, n, t+k) T_{S, M}(n, t+k)\right. \\
\left.-\hat{\psi}_{M}(k) P_{B, M}(m, n, t+k) T_{B, M}(n, t+k)\right] \\
+\sum_{k=1}^{N_{c}} \sum_{m=1}^{M}\left[\psi_{D}(k) P_{S, D}(m, t+k) T_{S, D}(m, t+k)\right. \\
\left.-\hat{\psi}_{D}(k) P_{B, D}(m, t+k) T_{B, D}(m, t+k)\right]
\end{array}
$$

As described in Fig.2, each terms within the objective function are associated with energy offered or bought. the first term subject neighboring MGs and the second one subjects the DSO.

\section{Optimization control algorithm}

A nonlinear centralized optimization is used to formulate the energy management in MG [13]. The cost function $C$ to be minimized is made without prediction with an one hour step for OCCA.

\section{MPC algorithm procedures}

MPC technology has the proven ability to provide control solutions using constraints, feed-forward, and feedback to handle multivariable processes with delays and processes with strong interactive loops. These types of control problems have successfully been handled in many industrial applications. Every control system is subject to have constraints. Via dealing with of constraints, MPC can enhance the overall performance of a system by permitting it to securely perform close to constraint boundaries. to use MPC, some steps need to be followed. At the first step of time $t$, the system at actual state is taken as the preliminary point of the problem as the RES, ESS, loads, power generation. Then, for the control horizon $N_{c}$ we compute an optimum control series for the following prediction duration $N_{p}$ based on RES, ESS, loads, power generation further to the prediction of energy rate. After that the first control step of all MGs might be applied. At the end, an update is made for all of the data for subsequent time step at the same time as shifting to the following sampling time to re-apply the same optimization.

\section{E. Constraints}

First, MG cannot buy and sell energy at the same time. buying can be done when the MG is in need of power otherwise MG can sell power when its production is higher than its consumption:

- If $\Delta P_{M G, n}(t+k)>0$ then $P_{B, D}(m, t+k)=0$ and $P_{B, M}(n, m, t+k)=0$

- If $\Delta P_{M G, n}(t+k)<0$ then $P_{S, D}(m, t+k)=0$ and $P_{S, M}(n, m, t+k)=0$

with $\Delta P_{M G, n}(t+k)=\sum\left(P_{E P, n}(t+k)-P_{E L, n}(t+k)\right)$, Where
- $\Delta P_{M G, n}$ : Power equilibrium of $\mathrm{n}$-th $\mathrm{MG}$ at $(t+k)$ instant.

- $P_{E P, n}$ : Power of the expected production of $\mathrm{n}$-th $\mathrm{MG}$ at time instant $(t+k)$.

- $P_{E L, n}$ : Power of the expected load of n-th MG at time instant $(t+k)$.

We must consider that the power sold by the m-th MG is equal the power bought by the $n$-th $\mathrm{MG}$ :

$$
P_{B, M}(m, n, t+k)=P_{S, M}(n, m, t+k)
$$

An upper and a lower bound $\left(P_{S, D, \min }, P_{S, D, \max }\right)$ constrained the predicted power sold to the DSO in each MG:

$$
P_{S, D, \min } \leq P_{S, D}(m, t+k) \leq P_{S, D, \max }
$$

An upper and a lower bound $\left(x_{m, \min }, x_{m, \max }\right)$ constrained the stored energy in each ESS. In the m-th MG:

$$
x_{m, \min } \leq x(m, t+k) \leq x_{m, \max }
$$

Also the predicted power bought from the DSO is also constrained by an upper and lower bound $\left(P_{B, D, \min }\right.$, $\left.P_{B, D, \max }\right)$

$$
P_{B, D, \min } \leq P_{B, D}(m, t+k) \leq P_{B, D, \max }
$$

The discharging power must be lower than certain limited power value $P_{\text {dismax }, m}$ :

$$
0 \leq P_{\text {dis }}(m, t+k) \leq P_{\text {dismax }, m}
$$

Also the charging power must be lower than certain limited power value $P_{\text {charmax }, m}$ :

$$
\begin{aligned}
& 0 \leq P_{\text {char }}(m, t+k) \leq P_{\text {charmax }, m} \\
& \text { IV. A CASE STUDY APPLICATION }
\end{aligned}
$$

A. Network's description

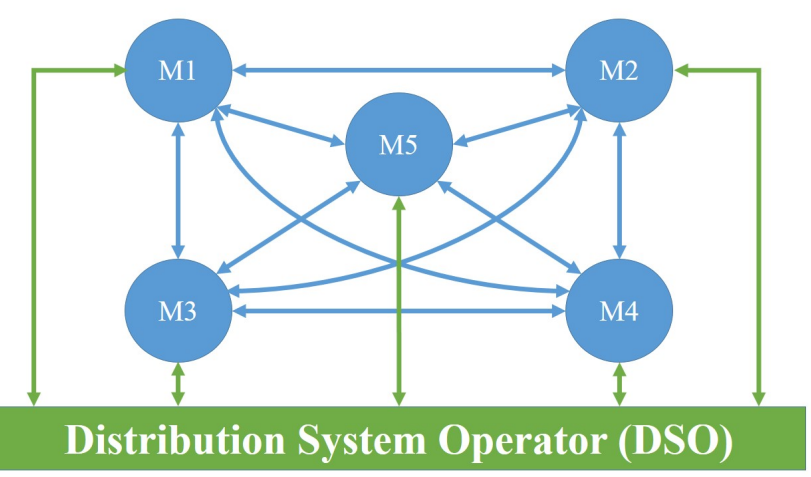

Fig. 3. Network topology example

To test the model described in previous section, the following example is used. A network of five connected MGs is observed, where the interconnection of each MG includes the DSO and the other four MGs. A single DSO is supposed to be connected to all MGs and the power exchange is bidirectional. A group of renewable energy, diesel generator, ESS and loads compose the MGs. 
In MPCA, the length of the prediction horizon $N_{p}$ is set to 24 hours and the length of the control horizon $N_{c}$ is equal to $3 \mathrm{~h}$. Various conditions of ESS are tested like fully charged or empty power, for various MGs. OCCA is simpler version algorithm where the control interval is set equal to 1 hour.

\section{B. Numerical values}

The Table I gives the values used in simulation. it gives global values for some characteristics of ESS and some power constraints such the minimum of sell/buy power for each microgrid. The capacity of the ESS available in each MG is comprised between 20 and $100 \mathrm{kWh}$. For each MG, the maximal charge and maximal discharge powers are limited. As example, MG2 can discharge in more than one hour $\left(\delta_{d i s, m}=0.7\right)$ and need 2 hours to be fully charged $\left(\delta_{\text {cha,m }}=0.2\right)$. In Fig. 4, we show the predicted value

\begin{tabular}{|c|c|c|c|c|c|}
\hline & MG1 & MG2 & MG3 & MG4 & MG5 \\
\hline$P_{S, D, \min }(\mathrm{kW})$ & 450 & 550 & 600 & 350 & 450 \\
$P_{B, D, \min }(\mathrm{kW})$ & 400 & 400 & 450 & 500 & 450 \\
ESS initial(kW) & 80 & 70 & 40 & 30 & 20 \\
$x_{m, \max }(\mathrm{kW})$ & 100 & 90 & 100 & 95 & 90 \\
$\delta_{\text {dis }, m}$ & 0.7 & 0.7 & 0.8 & 0.8 & 0.5 \\
$\delta_{\text {cha,m }}$ & 0.7 & 0.5 & 0.6 & 0.5 & 0.3 \\
\hline
\end{tabular}

TABLE I

NUMERICAL VALUES USED FOR SIMULATION.

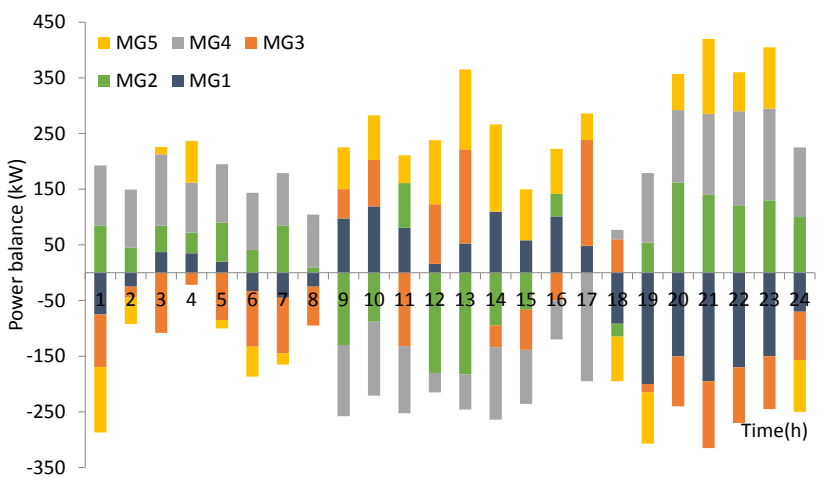

Fig. 4. MGs power equilibrium.

of $\Delta P_{M G}$ for each MG. The value is calculated based on the load and production curves of [13] where some random calculation are made in order to create more MGs.

As for the tariff vector of selling and buying energy, ( $T_{B, M}$, $\left.T_{S, M}, T_{S, D}, T_{B, D}\right)$ are represented for each $\mathrm{MG}$ in a random value between $0.065 € / \mathrm{kWh}$ and $0.18 € / \mathrm{kWh}$ from $6 \mathrm{am}$ to midnight, and $0.075 € / \mathrm{kW}$ from midnight to $6 \mathrm{am}$ (Fig. 5). The ESS can go down from $90 \%$ to $15 \%$ of power storage. In each MG, the power of ESS is different than the other. The sold/bought power from/to DSO is limited to $200 \mathrm{kWh}$ for each MG. The optimization algorithm searches to use the excess power available in each MG, under constraints, and to be exchanged. If the constraints are not satisfied, the DSO interferes while respecting its constraints.

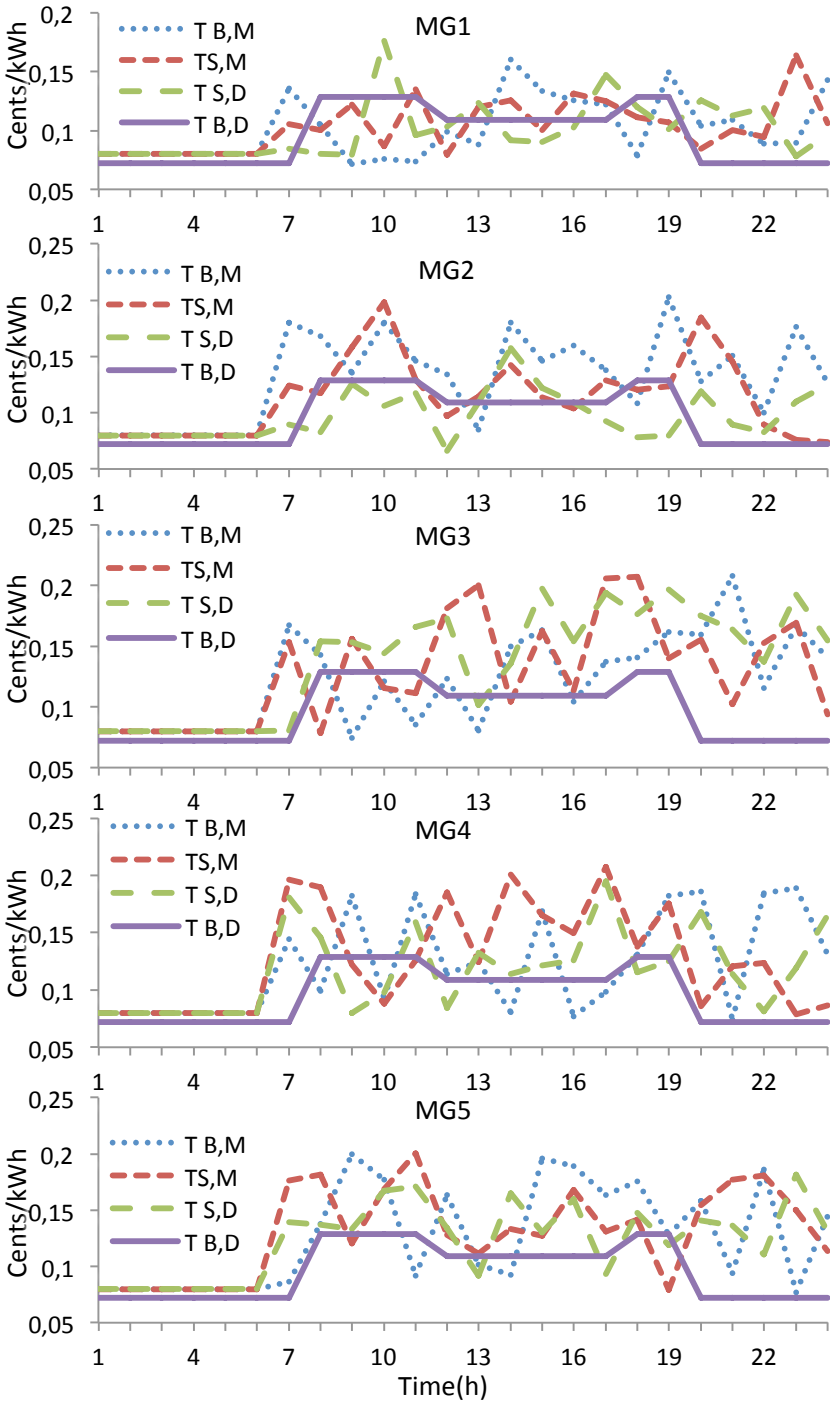

Fig. 5. The tariff vector.

\section{Simulation results}

Using MATLAB, the above described optimization problem has been resolved. A modified version of the study case presented in [13] has been used.

Each MG generates power and feeds a group of consumer in an interval time $(t, t+1)$. Also, it is connected to all neighboring MGs. Five interconnected MGs are taken in consideration in the simulation with $N_{c}=3$ and $N_{p}=24$ for the MPCA. When the supply in a MG is less the demand, the solution is to purchase power from many neighbors MGs or DSO, or to discharge the ESS.

1) MG1 simulation results: The OCCA results shown in Fig. 6 gives an overview about the interaction of MG1 with the other MGs. As result of selling and buying, MG1 sells $578 \mathrm{kWh}$ in total especially $235 \mathrm{kWh}$ to MG2 and $167 \mathrm{kWh}$ to MG3 and finaly to MG4 176kWh.In addition, MG1 buys 235kWh from MG2, $158 \mathrm{kWh}$ MG4, and 224kWh MG5. So in total, MG1 buys $617 \mathrm{kWh}$. The results obtained by the application MPCA shown in Fig.7 gives an overview 
about the interaction of MG1 with the other MGs. As result of selling and buying, MG1 sells $396 \mathrm{kWh}$ in total especially $102 \mathrm{kWh}$ to MG2 and $94 \mathrm{kWh}$ to MG3, 35kWh for MG5 and finally to MG4 160kWh. In addition, MG1 buys $112 \mathrm{kWh}$ from MG2, 99kWh from MG4,50kWh from MG3 and 64kWh MG5. So in total, MG1 buys 391kWh. Fig. 8

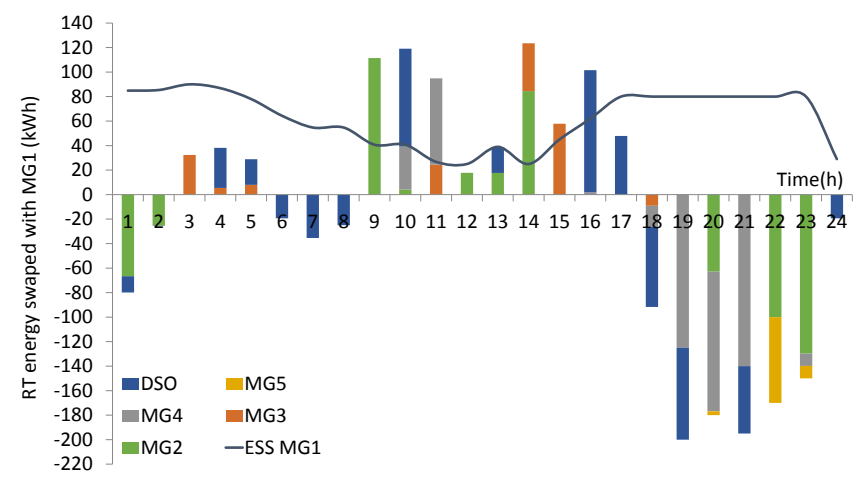

Fig. 6. OCCA results for MG1.

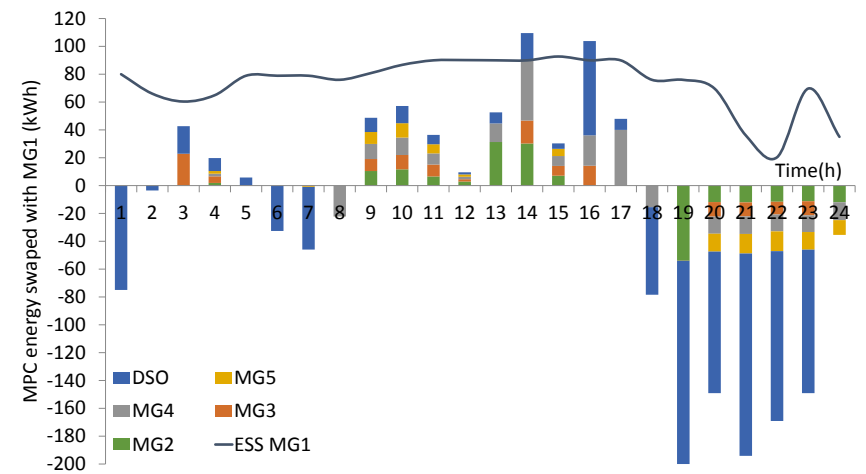

Fig. 7. MPCA results for MG1.

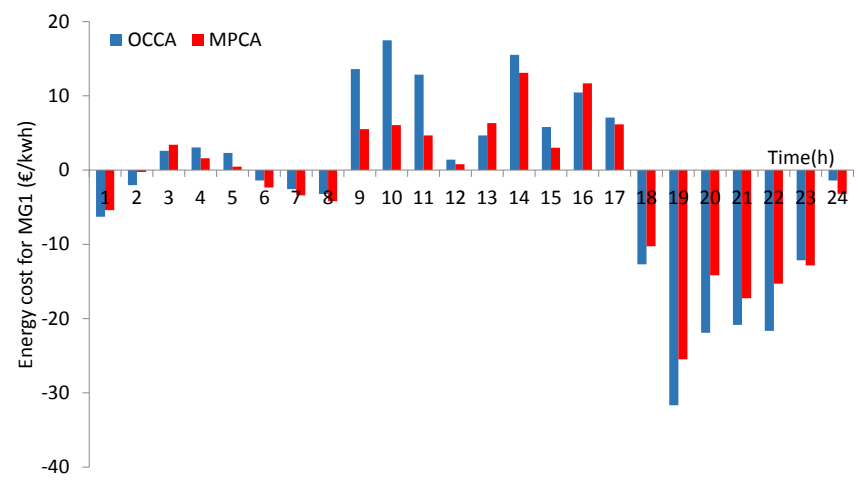

Fig. 8. OCCA vs MPCA cost for MG1.

shows the cost of purchasing/selling power from/to MG1 for OCCA and for MPCA. It gives an idea about the benefit for MGs and DSO using this two algorithm separately. Using MPCA the bought power is cheaper than OCCA. In other hand OCCA returns more benefit in selling excess power.

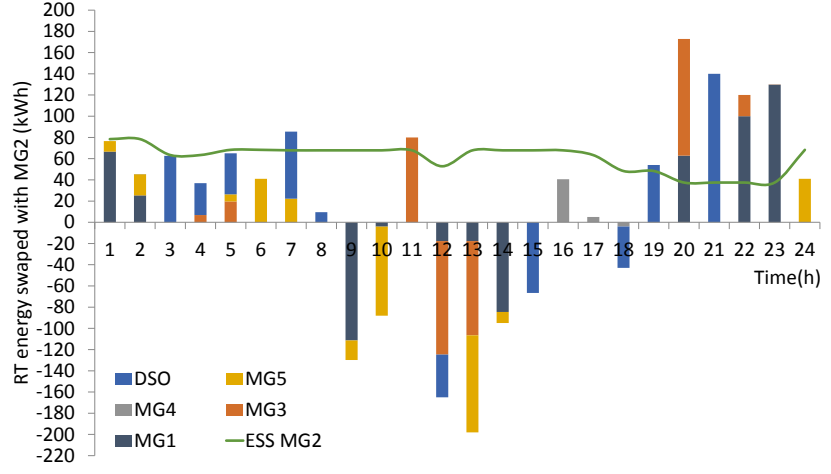

Fig. 9. OCCA results for MG2.

2) MG2 simulation results: Fig.9 shows the OCCA energy exchanges of MG2. The total energy bought is 871 $\mathrm{kWh}$, the main bought energy is from MG3 with 526kWh, the rest of bought energy comes from MG1 and MG5 with $235 \mathrm{kWh}$ and $110 \mathrm{kWh}$ respectively. Fig. 10 shows the MPCA

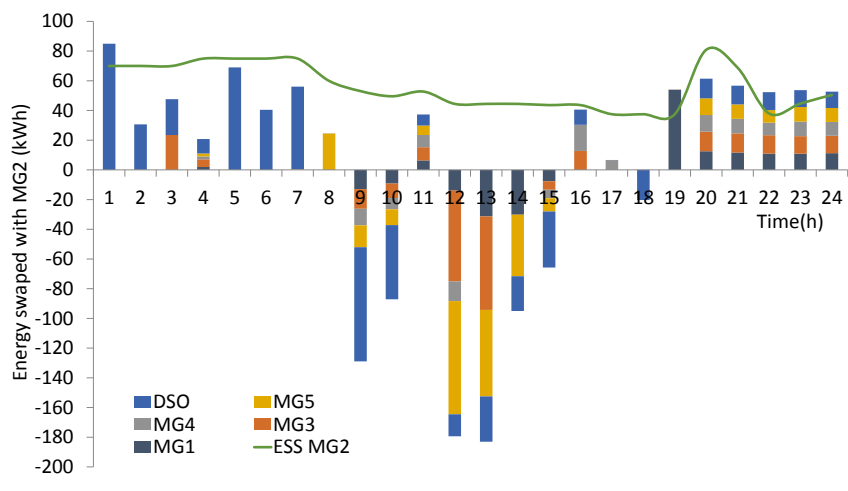

Fig. 10. MPCA results for MG2.

optimal energy exchanges of MG2. The total energy bought is $405 \mathrm{kWh}$, the main bought energy is from MG5 with $150 \mathrm{kWh}$, the rest of bought energy comes from MG1 and MG3 with $105 \mathrm{kWh}$ and $107 \mathrm{kWh}$ respectively. The cost of

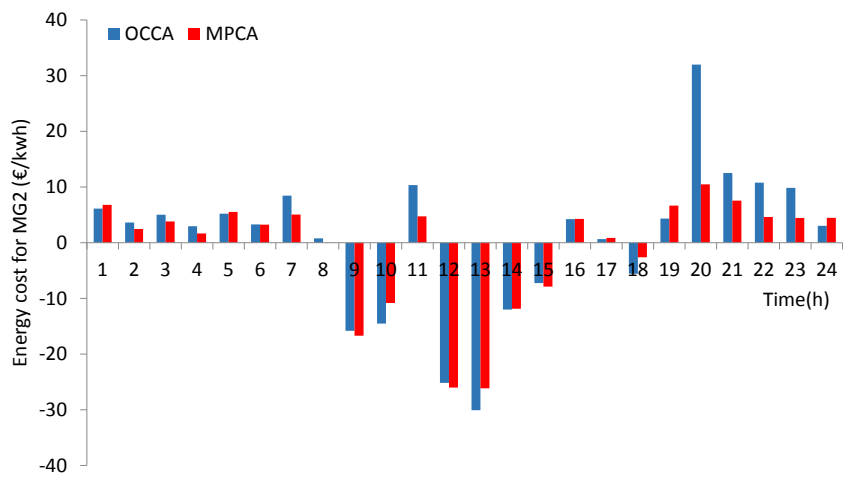

Fig. 11. OCCA vs MPCA cost for MG2.

applying the OCCA for MG2 (Fig.11) is more expensive then the MPCA. The MPCA show a reduction for the cost 
of purchasing energy specially for the time interval between 10 and 14.

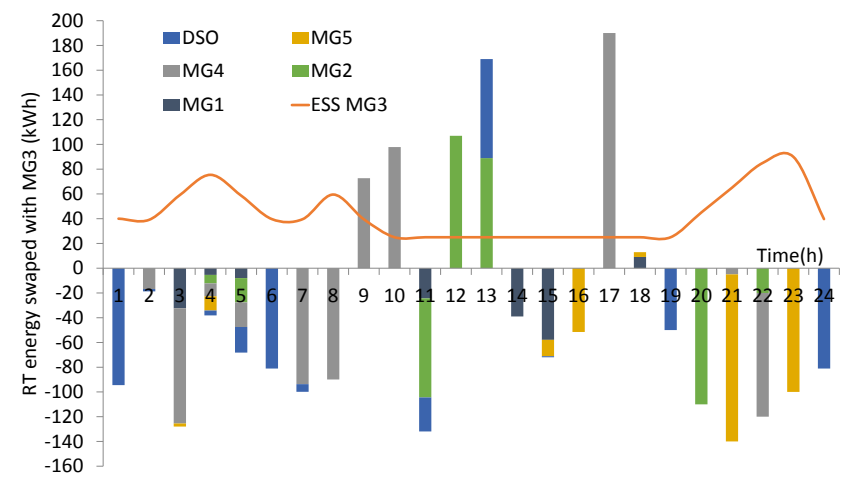

Fig. 12. OCCA results for MG3.

3) MG3 simulation results: OCCA for MG3 is shown Fig.12. It is obvious that MG3 buys energy more than selling. In total, it buys $1109 \mathrm{kWh}$ from other MGs where the main amount comes from MG2 with $526 \mathrm{kWh}$, from MG1 $167 \mathrm{Kwh}, 323 \mathrm{Kwh}$ from MG4, and 93kWh from MG5. It sells a small amount of $365 \mathrm{kWh}$ in total, distributed between MG2 and MG4 with $195 \mathrm{kWh}$ and $170 \mathrm{kWh}$ respectively. MPCA energy strategy for MG3 is shown Fig.13. It is

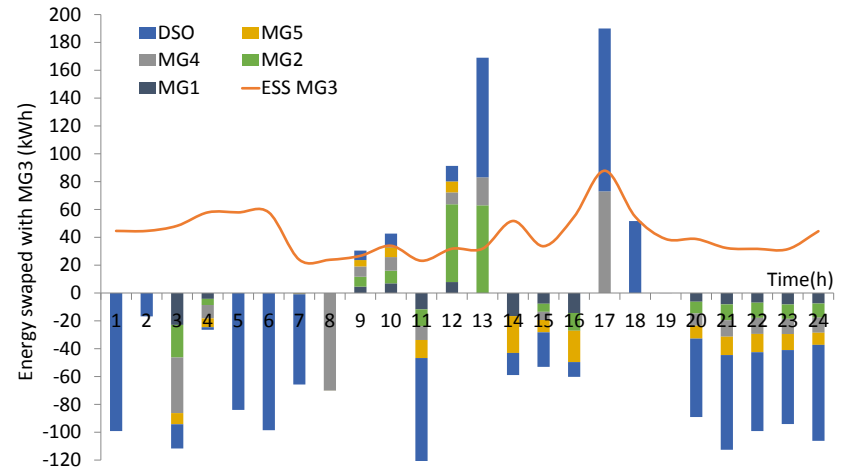

Fig. 13. MPCA results for MG3.

obvious that MG3 buys energy more than selling. In total, it buys $563 \mathrm{Kwh}$ from other MGs where the big amount comes from MG4 with 190kWh, from MG5 141KWh, 109KWh from MG2, and $114 \mathrm{kWh}$ from MG1. It sells an amount of 250KWh in total, distributed between MG2 and MG4 with $90 \mathrm{kWh}$ and $119 \mathrm{kWh}$ respectively.

Figure 14 shows that the MPCA is globally more suitable in cost term to be in use instead of the OCCA. For 24 hours MG3 pay $84 €$ in OCCA, and $37 €$ for the MPCA. The benefit in this case is more than $50 \%$.

4) MG4 simulation results: For MG4 in OCCA (Fig.15), the sold energy represents $616 \mathrm{kWh}$ where MG1 buys 158 $\mathrm{kWh}$, MG3 buys $323 \mathrm{kWh}$ and MG5 buys $134 \mathrm{kWh}$. Total bought energy is purchased from MG1 with $175 \mathrm{kWh}$, MG2 $170 \mathrm{kWh}$ and MG5 $218 \mathrm{kWh}$.

For MG4 (Fig.16), the sold energy represents $422 \mathrm{Kwh}$ where MG3 buys $192 \mathrm{Kwh}$, MG1 buys $107 \mathrm{kWh}$ and finally

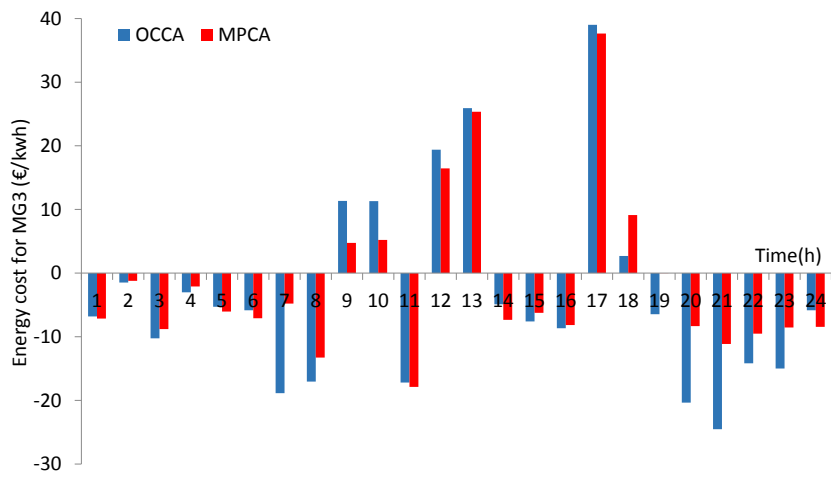

Fig. 14. OCCA vs MPCA cost for MG3.

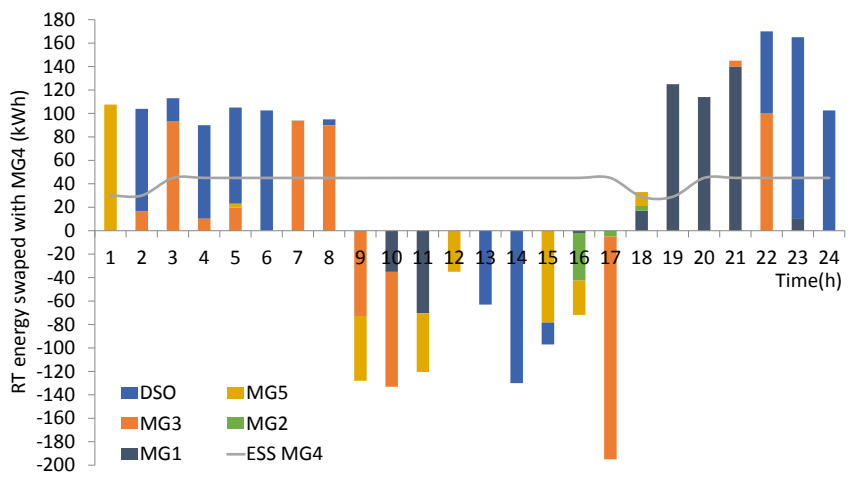

Fig. 15. OCCA results for MG4.

MG5 and MG2 buy 58kWh for each one. Total bought energy is purchased from MG1 with $168 \mathrm{kWh}, \mathrm{MG} 268 \mathrm{kWh}$, MG3 141kWh and MG5 188kWh in MPCA.

With a difference of $196 \mathrm{Khw}$ of sold energy (Fig.17) OCCA is preferred on the MPCA even the similarity of purchased power (563 kWh for optimal control, $565 \mathrm{kWh}$ for MPC).

5) MG5 simulation results: With OCCA MG5 represents the maximum benefit of sold/bought energy to other MGs with a total 740/243 kWh (Fig.18). Also in MPCA, MG5 has the maximum benefit of sold/bought energy with a total of 668/57kWh (Fig.19).

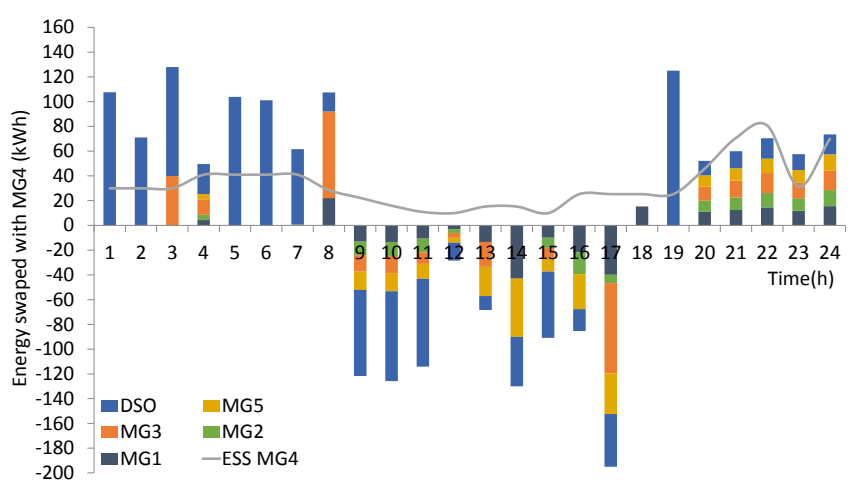

Fig. 16. MPCA results for MG4. 


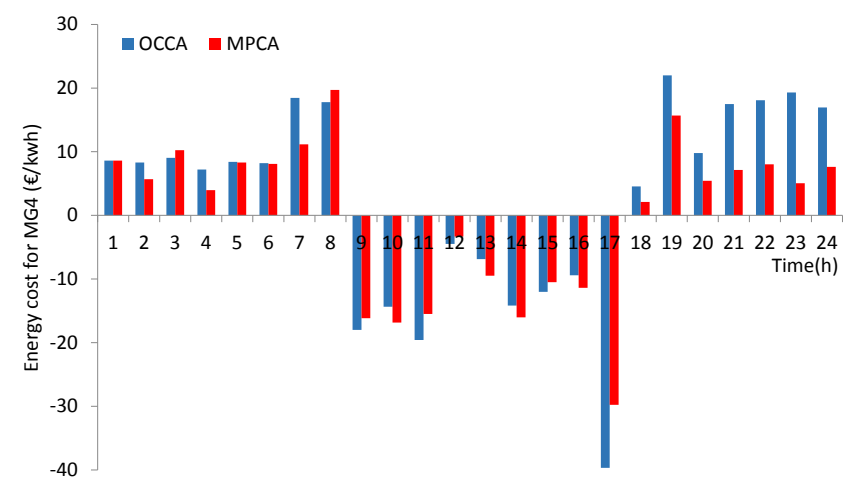

Fig. 17. OCCA vs MPCA cost for MG4

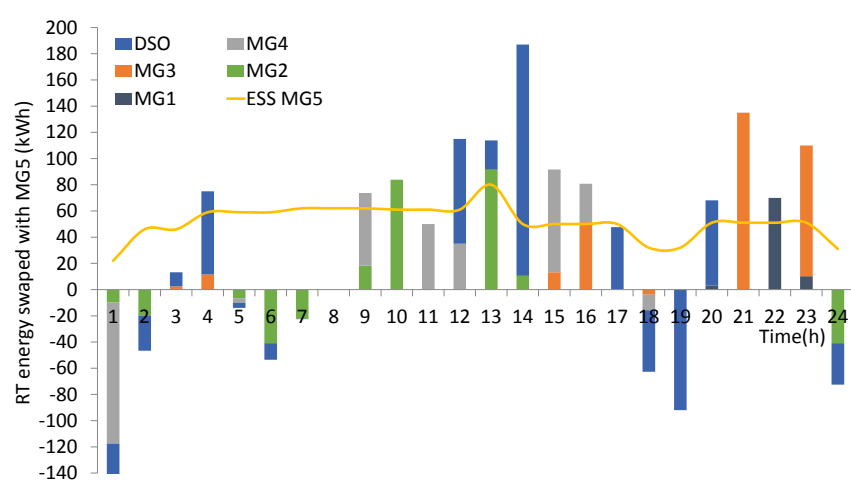

Fig. 18. OCCA results for MG5.

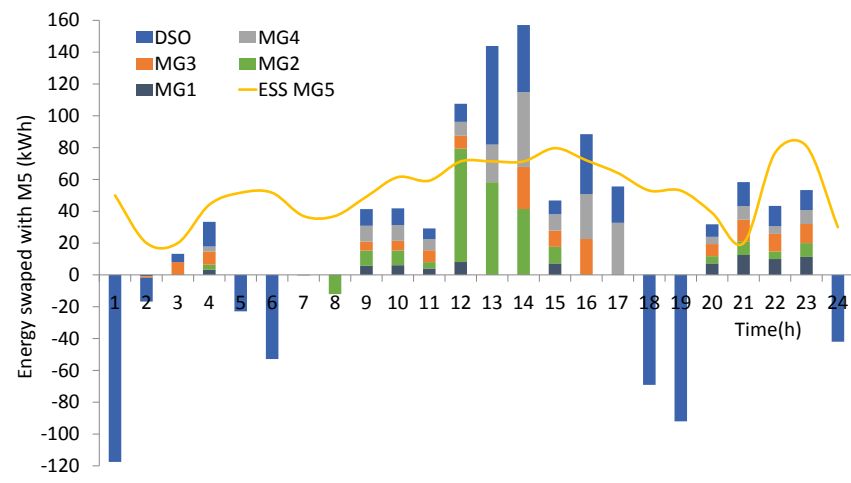

Fig. 19. MPCA results for MG5.

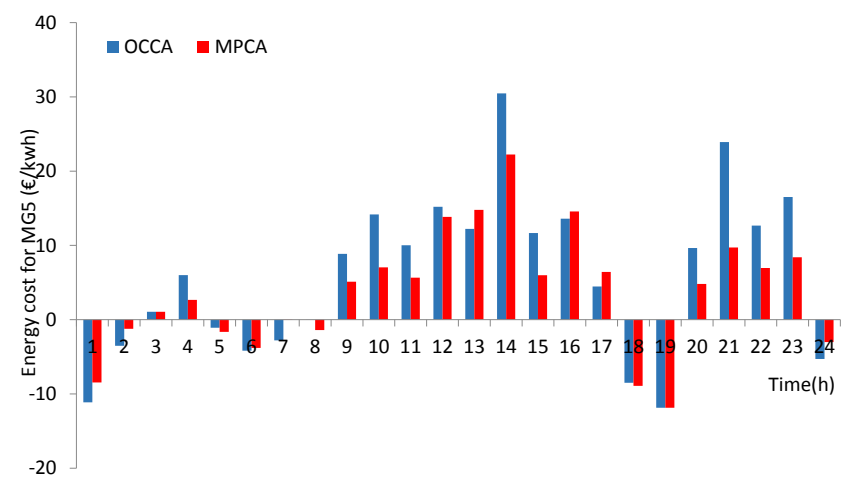

Fig. 20. OCCA vs MPCA cost for MG5.
The cost of energy exchange for MG5, Fig.20, in OCCA is cheaper then MPCA even that a $114 \mathrm{Kwh}$ more sold by MG5 in MPCA.

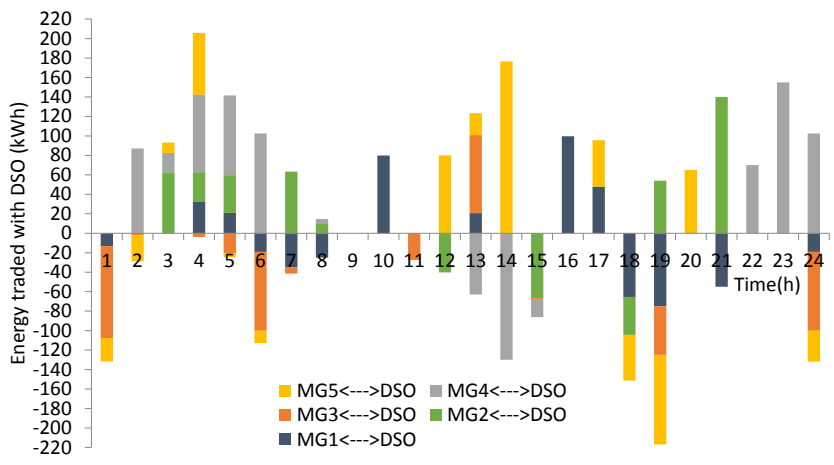

Fig. 21. OCCA power exchange with DSO.

6) DSO simulation results: Fig.21 and Fig.22 give the interaction between MGs and DSO in terms of power exchange in OCCA and MPCA respectively. It's obvious that in MPCA there is more exchange of power than in OCCA.

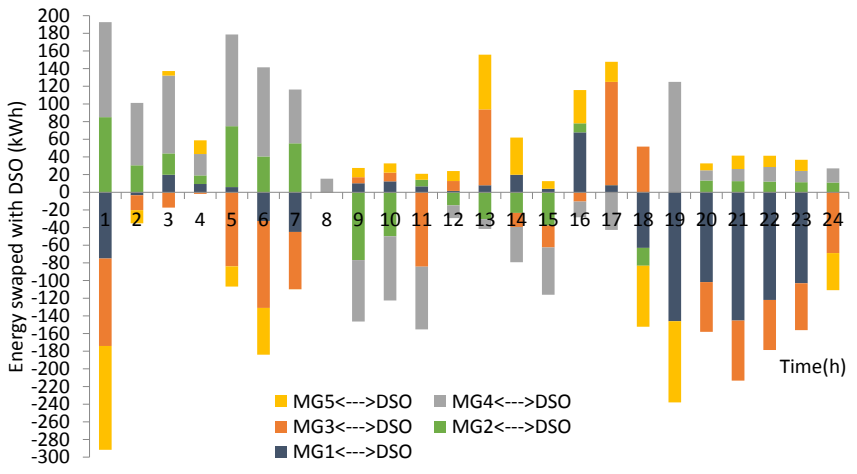

Fig. 22. MPCA power exchange with DSO.

7) ESS simulation results: Finally, Fig.23 and Fig.24 reveal the charge and discharge of ESS in each MG for OCCA and MPCA respectively.

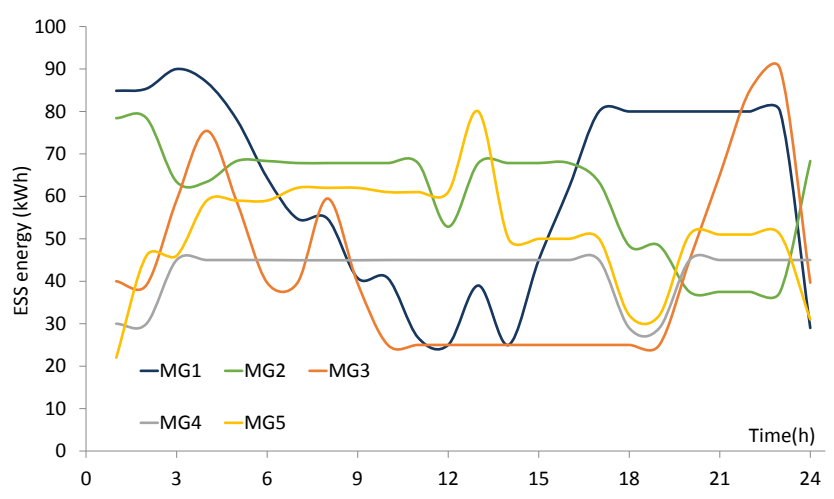

Fig. 23. OCCA charge and discharge of ESS. 


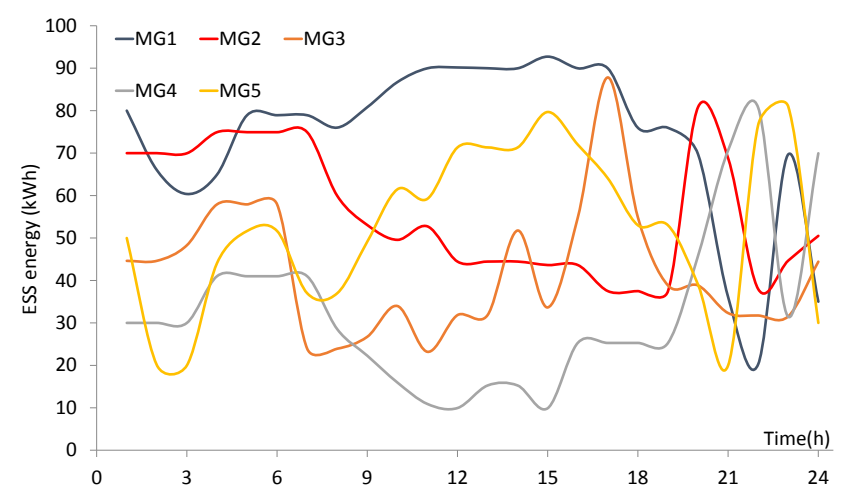

Fig. 24. MPCA charge and discharge of ESS.

\section{Discussion on the results}

ESS state of charge of MG5 on Fig.24 shows between the hour 15 and 21 a discharge and between the hour 21 and 23 charge respectively. The discharge is due to the need of power at this time in MG5 when the power production can't cover the load. The CU gives a command to charge the ESS of MG5 when the demand is covered by MG5 production unit or by purchasing power from neighboring MGs. On the same graph, it's clear that the ESS value couldn't exceed the $90 \%$ of its total value, nor going beyond $15 \%$. A similar analysis can be done for other MGs. ESS state of charge of MG5 on Fig. 23 shows a discharge between hour 17 and 19, it's charging between hour 19 and 20. the behavior of the SOC of each ESS depends in each method on the prediction of the microgrid elements.

\section{CONCLUSION}

The paper presents a MPCA vs OCCA in a centralized manner to optimize the interaction between a network of MGs and DSO. In both methods, by maximizing the benefits of all the constituted elements of network, the control performance of a network of MGs is achieved. The results show the predicted interaction of power exchange between MGs and the control of the ESS discharging/charging. The cooperation between MGs demonstrates its importance due to its benefit according the selling of the excess of power produced or its operation in standalone mode. According to the results the MPCA seems more beneficial for the micgrid elemets than the OCCA due to the forcasting information about production power, energy price and loads. A decentralized version of this algorithm is under study.In case of failure of communication between MGs, this control strategy can be the solution.

\section{REFERENCES}

[1] H. Al-Nasseri, M. Redfern, and R. O'Gorman, "Protecting micro-grid systems containing solid-state converter generation," in Future Power Systems, 2005 International Conference on. IEEE, 2005, pp. 5-pp.

[2] K. Hajar, A. Hably, S. Bacha, A. Elrafhi, and Z. Obeid, "Optimal centralized control application on microgrids," in International Conference on Renewable Energies for Developing countries. IEEE, 2016.
[3] J. Shah, B. F. Wollenberg, and N. Mohan, "Decentralized power flow control for a smart micro-grid," in Power and Energy Society General Meeting, 2011 IEEE. IEEE, 2011, pp. 1-6.

[4] J. L. Yue Xiang and Y. Liu, "Robust energy management of microgrid with uncertain renewable generation and load," in IEEE TRANSACTIONS ON SMART GRID. IEEE, 2015, pp. 1-10.

[5] L. D. Ahmed Ouammi, Hanane Dagdougui and R. Sacile, "Coordinated model predictive-based power flows control in a cooperative network of smart microgrids," in IEEE TRANSACTIONS ON SMART GRID. IEEE, 2014, pp. 1-12.

[6] A. N. Venkat, I. A. Hiskens, J. B. Rawlings, and S. J. Wright, "Distributed mpc strategies with application to power system automatic generation control," Control Systems Technology, IEEE Transactions on, vol. 16, no. 6, pp. 1192-1206, 2008.

[7] K. Hajar, A. Hably, S. Bacha, A. Elrafhi, and Z. Obeid, "An application of a centralized model predictive control on microgrids," in 2016 IEEE Electrical Power and Energy Conference (EPEC), Oct 2016, pp. 1-6.

[8] K. De Brabandere, B. Bolsens, J. Van den Keybus, A. Woyte, J. Driesen, and R. Belmans, "A voltage and frequency droop control method for parallel inverters," Power Electronics, IEEE Transactions on, vol. 22, no. 4, pp. 1107-1115, 2007.

[9] M. E. M. Falahi, S. Lotfifard and K. Butler-Purry, "Decentralized energy management system for networked microgrids in grid-connected and islanded modes," in IEEE TRANSACTIONS ON POWER. IEEE, 2013, pp. 2217-2227.

[10] J. W. Zhaoyu Wang, Bokan Chen and J. Kim, "Dynamic model predictive-based energy management of $\mathrm{dg}$ integrated distribution systems," in IEEE TRANSACTIONS ON SMART GRID. IEEE, 2015, pp. $1-10$.

[11] A. J. del Real, A. Arce, and C. Bordons, "An integrated framework for distributed model predictive control of large-scale power networks," Industrial Informatics, IEEE Transactions on, vol. 10, no. 1, pp. 197209, 2014.

[12] K. Hajar, A. Hably, A. Elrafhi, Z. Obeid, and S. Bacha, "Optimization of a microgrid with renewable energy and distributed generation: A case study," in System Theory, Control and Computing (ICSTCC), 2015 19th International Conference on. IEEE, 2015, pp. 662-665.

[13] A. G. Tsikalakis and N. D. Hatziargyriou, "Centralized control for optimizing microgrids operation," in 2011 IEEE power and energy society general meeting. IEEE, 2011, pp. 1-8. 